\title{
UTILIZAÇÃO DO ROBÔ CUBETTO EM UM PROCESSO DE FORMAÇÃO DOCENTE PARA PROFESSORES DA EDUCAÇÃO BÁSICA NA ÁREA DA ROBÓTICA EDUCACIONAL
}

\author{
USING THE CUBETTO ROBOT IN A TEACHER TRAINING PROCESS FOR BASIC \\ EDUCATION TEACHERS IN THE AREA OF EDUCATIONAL ROBOTICS
}

\author{
Rodrigo Segatto ${ }^{1}$, Adriano Canabarro Teixeira ${ }^{2}$
}

Recebido: abril/2020 Aprovado: novembro/2020

\begin{abstract}
Resumo: Cada vez mais, o avanço tecnológico do mundo moderno vem estreitando as relações entre a educação e as novas tecnologias, inserindo-as em sala de aula, seja com o professor ou com o aluno, contribuindo assim, para o processo de ensino e aprendizagem na construção do conhecimento. Neste cenário, a robótica é uma das tecnologias emergentes, composta por uma versatilidade capaz de proporcionar a interdisciplinaridade e tornar os estudantes agentes ativos em seu aprendizado. Nessa perspectiva, o objetivo deste trabalho foi apresentar o processo de elaboração de um produto educacional (sequência didática), desenvolvido a partir de uma formação docente para professores da educação básica na área de robótica educacional, a qual utilizou o Robô Cubetto e seus blocos de código programáveis em um processo de formação continuada de professores através da realização de oficinas de capacitação. Assim, na perspectiva desse trabalho, entendeu-se que a formação docente realizada permitiu aos professores a apropriação da tecnologia robótica apresentada, de maneira estes perceberam uma ferramenta multidisciplinar, capaz de atrair a atenção dos alunos nas idades iniciais e motivá-los a resolver problemas complexos, possibilitando um fazer educacional diferenciado através de uma prática pedagógica incentivadora.
\end{abstract}

Palavras-chave: robótica educacional, formação de professores, educação básica.

\begin{abstract}
Increasingly, the technological advancement of the modern world has been strengthening the relationship between education and new technologies, inserting them in the classroom, either with the teacher or the student, thus contributing to the teaching and learning process in the world. knowledge building. In this scenario, robotics is one of the emerging technologies, composed by a versatility capable of providing interdisciplinarity and making students active agents in their learning. From this perspective, the objective of this paper was to present the process of elaborating an educational product (didactic sequence), developed from a teacher training for teachers of basic education in the area of educational robotics, which used the Cubetto Robot and its blocks of programmable code in a process of continuing teacher education by conducting training workshops. Thus, from the perspective of this work, it was understood that the teacher training provided allowed teachers to appropriate the robotic technology presented, so they perceived a multidisciplinary tool, able to attract the attention of students in the early ages and motivate them to solve problems. complex, enabling a differentiated educational practice through an encouraging pedagogical practice.
\end{abstract}

Keywords: educational robotics, teacher training, basic education.

https://orcid.org/0000-0001-7700-8586 - Mestre em Ensino Científico e Tecnológico na Universidade Regional Integrada do Alto Uruguai e das Missões (URI - Santo Ângelo). Travessa Germano Mousquer, 201, BL06, AP 302, Bairro Casaroto, 98804-085, Rio grande Do Sul, Brasil. E-mail: segattorodrigo@hotmail.com

2 (iD https://orcid.org/0000-0002-7941-3515 - Pós-doutor em Educação na Universidade Federal do Rio Grande do Sul (UFRGS). Professor Titular na Universidade de Passo Fundo (UPF), Passo Fundo, Rio Grande do Sul, Brasil. Universidade de Passo Fundo, Instituto de Ciências Exatas e Geociências, Campus Universitário, Bairro São José, São José, 99001970, Passo Fundo, RS, Brasil, Caixapostal: 611. E-mail: teixeira@upf.br 


\section{Introdução}

A sociedade está cada vez mais diretamente dependente do emprego das ferramentas tecnológicas para realização de suas tarefas diárias, seja em ambiente de trabalho ou simplesmente como forma de lazer (AGUIAR et. al., 2015).

Neste contexto, de acordo com Reis, Leite e Leão (2017), com o avanço tecnológico e o advento da informatização das escolas, fica evidenciado cada vez mais o estreitamento entre as fronteiras da educação e das tecnologias, onde, em sala de aula, as ferramentas tecnológicas têm contribuído para a construção do conhecimento, seja por parte do professor quanto do aluno. De acordo com Dos Santos e Strohschoen (2018), novos debates na área da educação foram desencadeados a partir da inclusão e da disseminação das tecnologias em sala de aula e, como consequência destes debates, os profissionais da educação têm sido convidados a rever o papel da escola e do professor por um olhar concentrado e atento à novas estratégias de ensino, tendo em vista que os alunos de hoje pertencem a uma nova geração que já nasceu em meio às tecnologias digitais e seus fluxos intensos.

Resultados de pesquisas têm demonstrado que os jovens anseiam por novas propostas de práticas didáticas envolvendo as tecnologias, a exemplo do levantamento realizado pelo portal Porvir do Instituto Inspirar, denominado Nossa Escola em (Re)Construção ${ }^{1}$, que contou com a participação de 132 mil jovens de todos os estados, demonstrando através de seus resultados que os alunos desejam substituir aulas teóricas por aplicações de projetos que envolvam atividades práticas ou resolução de problemas, maior utilização da tecnologia em sala de aula e um currículo diversificado e flexível para uma escola inovadora que inclua em suas práticas a robótica, programação e games.

Estendendo esta questão para a robótica e programação de computadores, segundo De Oliveira (2014), trabalhos e projetos desenvolvidos já trazem a robótica no ensino de algoritmos e lógica de programação, permitindo controlar os robôs no meio físico através de blocos de códigos gráficos, proporcionando uma construção do conhecimento diferenciada, onde a pesquisa de Aguiar e outros (2015), demonstra que este tipo de ensino, contribui para aprendizado das outras disciplinas de modo geral, administrando melhor a resolução de problemas através da lógica e do conhecimento científico.

Segundo Ramos e Espadeiro (2014), o sucesso deste processo passa pela formação do professor. E frente aos desafios da escola moderna, em meio às desenfreadas mudanças neste campo, é primordial que as instituições de ensino oportunizem uma formação inicial aos futuros professores, assegurando que estejam preparados para suas missões de ensino, apropriados de uma formação científica e pedagógica sólida, moderna e atualizada para aos novos contextos educacionais.

Tendo em vista esses aspectos, com objetivo de ampliar o repertório didático dos professores na área da Informática Educativa apoiando-se em recursos da Robótica, o presente

${ }^{1}$ Nossa Escola em (Re)Construção - PORVIR." http://porvir.org/nossaescola/. Acessado em 29 set. 2018 
trabalho apresenta uma proposta formativa para utilização da robótica na educação básica, oferecendo contribuições para que os profissionais docentes possam adentrar-se na temática, apropriando-se dos conhecimentos adquiridos, aplicando-os em suas práticas em sala de aula, ao ponto que possam fortalecer o processo de ensino e aprendizagem, incentivando os alunos no desenvolvimento do raciocínio, da criatividade e da construção do conhecimento, bem como, fomentando os anseios destes por atividades práticas com a utilização de ferramentas tecnológicas.

O trabalho segue assim organizado: A Seção 2 discute a utilização da robótica como instrumento tecnológico de ensino nas escolas, bem como a importância da realização de formações docentes para sua utilização na educação básica; Na Seção 3 são apresentados os procedimentos metodológicos da pesquisa; A Seção 4 apresenta a sequência didática desenvolvida e as possibilidades de experiências para realização de uma formação docente; $A$ Seção 5 discute a formação prática realizada e os resultados obtidos e, por fim, na Seção 6 estão as conclusões e perspectivas desse trabalho.

\section{Informática Educativa, Robótica e a Formação Docente Para Utilização na Educação Básica}

Por trás dos discursos escolares contemplando a importância da tecnologia na educação, emerge o conceito de Informática Educativa, referindo-se ao privilégio do uso de ferramentas tecnológicas nas práticas pedagógicas do professor para auxiliar na construção do conhecimento. Ao associar as Tecnologias da Informação e Comunicação ao processo de ensino e aprendizagem estamos contribuindo para a socialização do saber e da informação do aluno, uma vez que este está cada vez mais ligado à tecnologia (MORAIS; MORAIS; MORAIS, 2018).

Em nosso cotidiano, a utilização de tecnologia vai muito além da educação. Nos deparamos frequentemente com máquinas e equipamentos robotizados desenvolvidos e aplicados como ferramentas para substituição da mão de obra humana nas indústrias e fábricas e, como consequência, gradativamente algumas profissões com habilidades muito específicas vão sendo consumidas por tecnologias cada vez mais avançadas. Este cenário permite uma reflexão, não somente sobre a importância das tecnologias aplicadas à educação, mas também, muito fortemente, acerca de como os professores irão priorizar a utilização de tecnologias, estudando-as e desenvolvendo-se para trabalhar outros aspectos do processo de aprendizagem dos alunos e o que deverão aprender, canalizando os esforços em um processo de ensino e aprendizagem fundamentado na resolução de problemas e no desenvolvimento da criatividade, permitindo aos alunos desde as séries iniciais, adaptarem-se a um mundo em transformação contínua no que diz respeito à evolução tecnológica e competitividade.

Quando os processos de ensino relacionados à informática educativa são pautados para este tipo de aprendizagem, podemos dizer que se está fomentando o Pensamento Computacional, compreendido por Glizt e Koscianski (2017), como métodos para a solução de problemas fundamentado nas técnicas da Ciência da Computação, sendo considerado uma das formas pelas quais é possível desenvolver o raciocínio lógico. 
Neste cenário de experiências utilizando as tecnologias digitais na educação, visando o desenvolvimento do pensamento computacional, destaca-se a robótica, portadora de um forte apoio lúdico, a qual, segundo Queiroz e Sampaio (2016), apresenta-se como uma opção de ensino multidisciplinar, permitindo aos alunos o desenvolvimento de uma diversificada gama de competências e habilidades, ao passo que engloba, através de um único objeto de estudo, diversas áreas do saber, como matemática, mecânica, inteligência artificial, programação de computadores, entre outras, contribuindo com propostas didáticas que a tornam um excelente recurso pedagógico ao professor.

Partindo destes princípios, a Primo Toys, fábrica de brinquedos inteligentes, criou o Kit de Codificação Cubetto, demonstrado na Figura 1, para ajudar crianças a descobrirem a programação de computadores longe das telas. O mesmo é uma interface de programação tangível, projetada para apresentar crianças de 3 a 6 anos ao pensamento computacional e à lógica de programação, permitindo que eles programem um pequeno robô de madeira usando blocos coloridos.

Figura 1 - Kit de Codificação Cubetto.

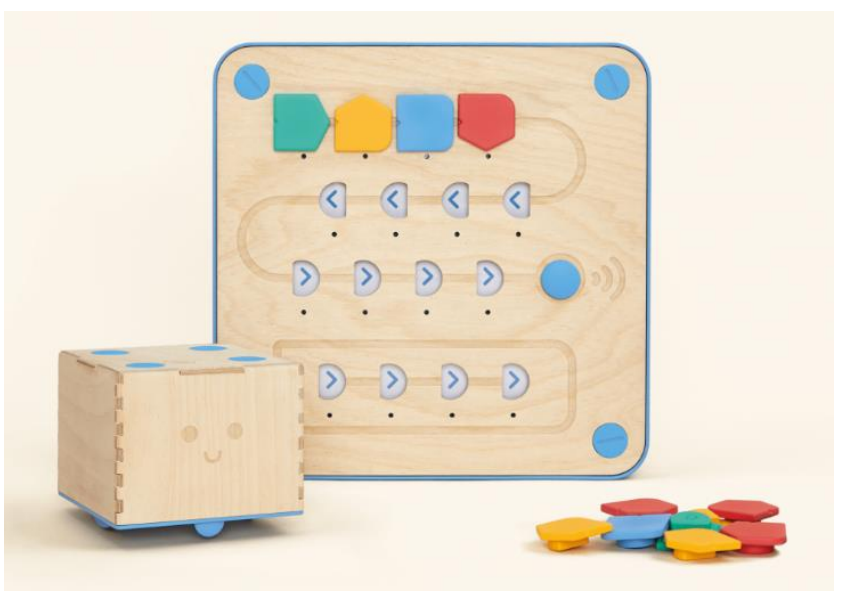

(Fonte: https://www.primotoys.com/)

Cubetto é um brinquedo composto de um conjunto de blocos eletrônicos de códigos coloridos que permite ensinar crianças a codificar antes mesmo de aprenderem a ler ou escrever, sem a utilização de telas ou interface digital (PRIMO, 2017). Esta forma de aprendizagem para crianças, proporcionada pelo Kit de Codificação Cubetto, permite controlar e manipular objetos concretos através de sequências lógicas, observando a materialização dos comandos dados a eles, formando o processo a partir do qual se estabelece a construção do seu conhecimento.

A abordagem já apresentada referente à informática educativa, de acordo com Lima e Moita (2011), nos coloca frente a uma realidade onde cada vez mais, as tecnologias são consolidadas na configuração de uma "caixa de ferramentas", apresentando-se através de diversas possibilidades, como instrumentos que podem auxiliar no desenvolvimento de novas formas de interação cultural, mediação escolar, favorecendo a elaboração e ampliação de processos pedagógicos que consigam aproximar os alunos à sua própria realidade, de modo que, a interação com o meio tecnológico é o conciliador fundamental deste processo. 
Neste sentido, os autores Lima e Moita (2011), apontam que faz-se necessário que o professor conheça e utilize as novas tecnologias, a fim de que possa trabalhar um fazer educacional que consiga manipular conteúdo de forma interativa e lúdica, abandonando o mero papel um dia the atribuído, que o colocava como um simples transmissor de conhecimento, passando a apresentar este conhecimento de forma inovadora e estimulante, deixando de ser apenas um objeto do processo de ensino e aprendizagem para ser o sujeito, o que, de fato, o ajudará no desenvolvimento do senso crítico frente a novos recursos e na melhoria de sua práxis.

\section{Procedimentos Metodológicos}

A abordagem metodológica desta pesquisa é uma abordagem qualitativa, visando a compreensão, descrevendo e explicando a percepção dos professores perante esta nova possibilidade de ensino e refletindo sobre como os alunos podem ser beneficiados a partir desta nova tecnologia, se caracterizando como uma pesquisa aplicada, uma vez que está preocupada com a utilização imediata de seu resultado e consequência de sua utilização.

O desenvolvimento da parte empírica desta pesquisa foi realizado junto a um grupo de professores do ensino fundamental, onde foram realizadas oficinas previamente planejadas na sequência didática que norteou o processo - e que teve parte da sua construção durante o andamento das atividades -, ocupando dois turnos de trabalho, através dos quais foram realizadas todas as atividades práticas previstas para a formação, acrescido de um turno para as entrevistas, que foram realizadas com os professores após o processo de formação docente.

Os participantes desta pesquisa, compuseram um grupo de 6 sujeitos, importante para uma escola de pequeno porte, onde conseguiram participar do processo professores que trabalham com a educação básica, bem como demais professores com afinidade e interesse pela temática do estudo.

\section{Sequência Didática}

A Sequência Didática desenvolvida, demonstrada na Figura 2, encontra-se dividida em cinco módulos, e tem o intuito de colaborar como instrumento de ensino que possa orientar os docentes na construção de situações de aprendizagem com recursos didáticos voltados para a utilização da Robótica Educacional na Educação Básica. Para tanto, a Sequência Didática apresenta as etapas de um processo formativo que, além de situar os sujeitos acerca do contexto da pesquisa, utiliza o Robô Cubetto como objeto chave.

Figura 2 - Módulos da Sequência Didática. (Fonte: Autor)

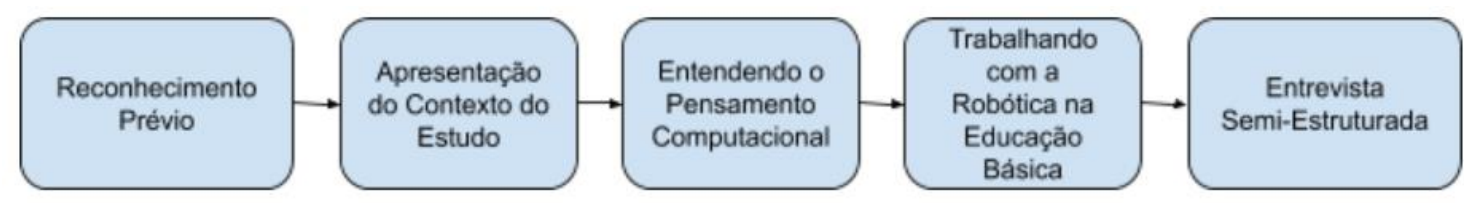


A Tabela 1 abaixo foi desenvolvida com o intuito de apresentar de maneira simplificada os módulos que envolvem a Sequência Didática, bem como os objetivos a serem alcançados em cada um dos módulos.

Tabela 1 - Estrutura da sequência didática elaborada.

\begin{tabular}{ll}
\hline \multicolumn{1}{c}{ Etapas } & \multicolumn{1}{c}{ Descrição } \\
\hline $\begin{array}{ll}\text { 1. Reconhecimento } \\
\text { Prévio }\end{array}$ & Diagnóstico buscando a compreensão \\
& do conhecimento prévio da turma a \\
& respeito da utilização da informática \\
& e suas tecnologias na educação \\
& básica, bem como a robótica \\
& educacional
\end{tabular}

2. Apresentação do Contexto do Estudo

\section{Entendendo o Pensamento Computacional}

4. Trabalhando com a
Robótica na
Educação Básica

Apresentar as teorias estudadas, contextualizando os conceitos apresentados no módulo 1 , situando os professores acerca da Informática na Educação e da Robótica Educacional, bem como a Robótica na educação Básica.

Apresentar os conceitos que envolvem o Pensamento Computacional, contemplando atividades práticas que consigam demonstrar as principais habilidades que apoiam o mesmo.

Realizar atividades práticas com o Kit de Codificação Cubetto, demonstrando como esta ferramenta robótica pode propiciar uma gama diversificada de trabalhos na educação básica

Realizar entrevista com os professores que participaram do processo didático e oficinas de formação docente.

\section{Objetivos}

Compreender como os professores participantes das oficinas de formação percebem o contexto educacional aqui estudado, dando subsídios, para que ao final o processo formativo seja possível fazer um paralelo entre as diferentes visões desde a etapa inicial.

Compreender o contexto da pesquisa de modo que os docentes consigam visualizar os assuntos, as problemáticas e as ferramentas da pesquisa como objetos auxiliadores na melhoria de suas práticas pedagógicas

Capacitar a turma para compreender os princípios e habilidades que formam o conceito de Pensamento Computacional, subsidiando o processo subsequente, com intuito de obter melhores resultados no processo de formação docente e uma aprendizagem mais significativa

Capacitar a turma em atividades educativas para a educação básica, realizando práticas com uma ferramenta robótica tangível, longe das telas do computador, tendo por principal finalidade, que os mesmos consigam apropriar-se deste recurso didático e compreender como tal objeto ou afins podem ser importantes auxiliadores para um fazer diferenciado no processo de ensino desde as idades iniciais.

Verificar se o processo formativo foi capaz de auxiliar os professores no reconhecimento da Robótica Educativa como recurso pedagógico e se conseguiram apropriar-se das possibilidades oferecidas pela área, compreender as possibilidades e benefícios da aplicação na Educação Básica.

Fonte: Autor. 


\section{Resultados}

Este capítulo apresenta os resultados da pesquisa, que buscou identificar como a formação docente pode permitir que professores se apropriem das possibilidades oferecidas pela robótica educativa no contexto da educação básica apoiados nos recursos oferecidos pelo Robô Cubetto e seu Kit de Robótica.

Os professores que participaram das oficinas de formação docente são vinculados, de acordo com a Base Nacional Comum Curricular - BNCC, às grandes áreas de Matemática, Ciências da Natureza e Ciências Humanas. Todos os professores são atuantes da Educação Básica, sendo que um trabalha diretamente com a Educação Infantil, outro que participou pela afinidade com o assunto trabalha com Ensino Médico e os demais, trabalham com o Ensino Fundamental nos Anos Iniciais ( 10 ao 50 ano).

Os parágrafos seguintes irão apresentar alguns dados e informações relativas ao trabalho de campo e às experiências vivenciadas nas oficinas, versando sobre as atividades realizadas e seus direcionamentos, demonstrando o conhecimento da turma de professores sobre o contexto estudado, suas opiniões e seus comportamentos perante às práticas realizadas e ao contato com a tecnologia da robótica sob um prisma de aplicação no contexto educacional juntamente aos anos iniciais de ensino.

\section{Conhecimento Prévio da Turma de Professores}

Durante o primeiro módulo, buscou-se compreender e determinar o conhecimento prévio da turma de professores em relação ao contexto do estudo, podendo assim, relacionar esses saberes às descobertas realizadas durante a prática nas oficinas de formação docente. Desta forma, antes de qualquer explicação, foram postos no quadro negro alguns questionamentos, os quais podem ser demonstrados na Figuras 3, de forma a identificar o conhecimento da turma de professores sobre as temáticas envolvendo Informática Educativa e Robótica Educacional, para as quais foram repetidos os seguintes questionamentos: O que é? Vantagens? Utilizam na escola? Como? Pode-se utilizar na educação básica? Como?

Figura 3 - Questões para conhecimento prévio sobre Informática Educativa.

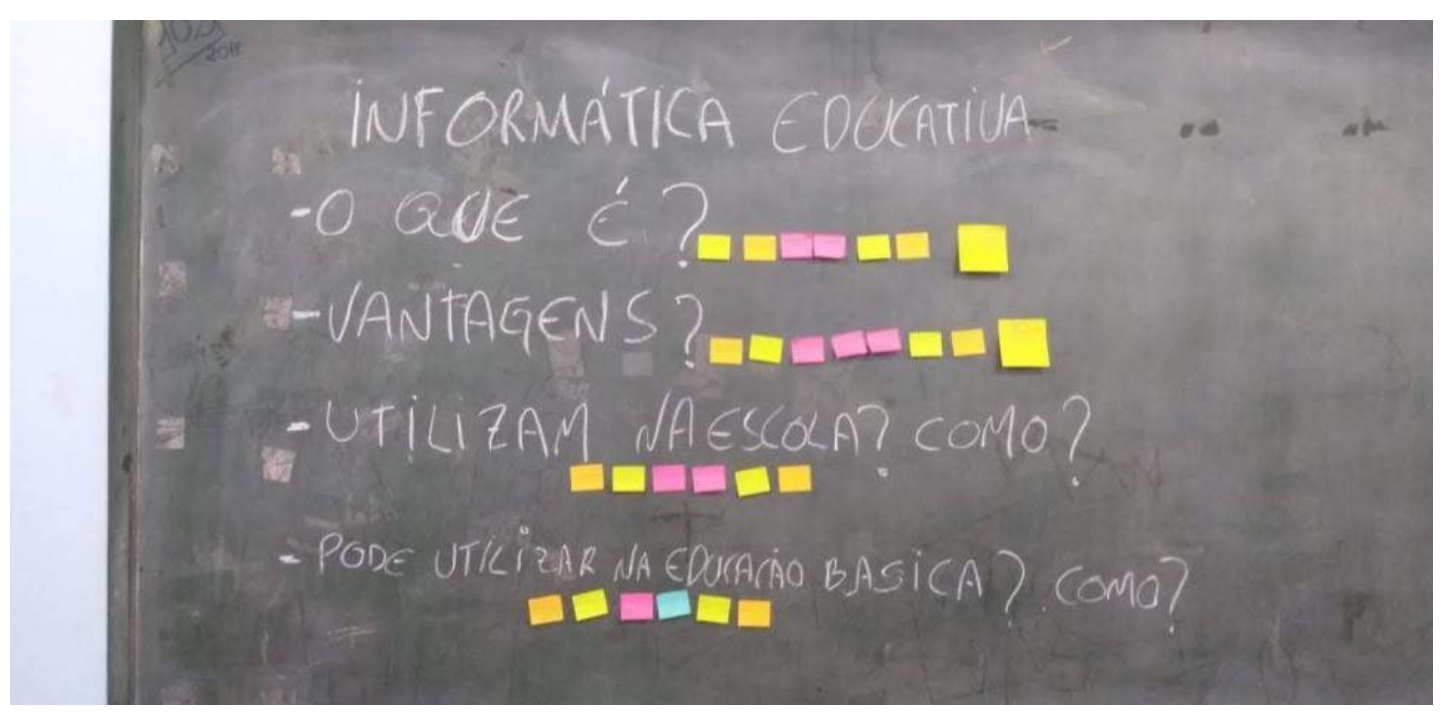

(Fonte: Autor) 
O pesquisador então, explicou o funcionamento da didática, onde iriam realizar uma atividade dinâmica, e que no primeiro ato, cada um, colocaria pelo menos um post-it respondendo a cada uma das questões, e por final, iriam finalizar com uma resposta conjunta que deveria ser discutida pela turma.

As respostas dos professores referente à Informática Educativa são demonstradas na Tabela 2.

Tabela 2 - Respostas da turma sobre Informática Educativa.

\begin{tabular}{ll}
\hline O que é? & INFORMATICA EDUCATIVA \\
& Uso da tecnologia para aprender; Planejada e orientada; \\
& Despertar interesse; Interesse pela tecnologia; Informação rápida; \\
& Conhecimento em tecnologia. \\
Definição Geral da Turma & Utilizar a tecnologia a serviço da educação. \\
Vantagens? & Acesso rápido; Desenvolver raciocínio e interesse; Avançar nas \\
& informações e pesquisas; Aprendizagem por meio de diferentes \\
& formas; Acesso à informação rápida; Atividade acessível; Desperta \\
& interesse. \\
Definição Geral da Turma & Despertar o interesse com acesso rápido. \\
Utilizam na escola? & Sim, Kahn Academy; Com jogos e músicas; Sim, laboratório de \\
& informática; Sim, pesquisas e jogos; Sim, jogos informativos; Sim, \\
& pesquisa de conteúdo e dados. \\
Pode-se utilizar na educação & Sim, com prática e conhecimento; Sim, jogos e pesquisa; Sim, \\
básica? Como? & Deve fazer parte do conhecimento de forma diferente; Sim, \\
& pesquisa prévia para complemento; Sim, através de jogos e \\
& pesquisas; Sim, jogos \\
\hline
\end{tabular}

Fonte: Autor.

Em se pronunciar a respeito de Informática Educativa, a turma de professores demonstrou com plenitude o conhecimento sobre o assunto, os quais, elencaram com exatidão, apesar das poucas palavras, o significado e a importância do tema no contexto educacional. Percebe-se também que a escola onde atuam, ainda que localizada em um pequeno município de interior, trabalha alguns aspectos da informática educativa, utilizando a sala de aula e o laboratório para pesquisas, jogos educativos, entre outros.

Ao mesmo tempo que demonstram realizar trabalhos neste sentido, a turma apresenta respostas com horizonte limitado em relação às possibilidades de utilização da informática educativa e suas tecnologias no contexto da educação básica, o qual, pode ser um reflexo da falta de habilidade e treinamento para apropriação de novos meios tecnológicos, conforme citado por uma das professoras que diz: "Tentamos muito utilizar o Notebook para algumas atividades, porém, muitas vezes, na hora da prática, ocorrem alguns problemas que não conseguimos resolver e acabamos por não utilizar novamente". E lembra a professora que diz: "que o professor deve estudar aquela determinada ferramenta que irá trabalhar, pois muitas vezes na hora as coisas não saem como planejado se faltar conhecimento e apropriação para manusear a mesma".

Para identificar o conhecimento dos professores com relação à Robótica educacional realizou-se novamente a dinâmica dos post-its e os resultados estão expressos na Tabela 3. 
Tabela 3 - Respostas da turma sobre Robótica Educacional.

\begin{tabular}{ll}
\hline O que é? & ROBÓtICA EDUCACIONAL \\
& $\begin{array}{l}\text { Programação; Robótica Caminha com a Informação; Construir; } \\
\text { Construção de Ferramenta pelos alunos; Tecnologia usada para } \\
\text { construir; Construção de ferramenta. }\end{array}$ \\
\hline Definição Geral da Turma & Planejar e construir algo. \\
Vantagens? & $\begin{array}{l}\text { Desperta criatividade; Desenvolver o raciocínio e criatividade; } \\
\text { Desenvolver o raciocínio do aluno; Desenvolver o raciocínio e } \\
\text { criatividade; Aprender brincando; Desenvolve o raciocínio. }\end{array}$ \\
Definição Geral da Turma & $\begin{array}{l}\text { Desenvolve o raciocínio e a criatividade do aluno de forma } \\
\text { lúdica. }\end{array}$ \\
Utilizam na escola? & Não; Não; Não; Não; Não; Não. \\
Pode-se utilizar na educação & Sim; Com certeza; Sim, não sei como; Sim; Pode se tiver \\
básica? Como? & treinamento e disponibilidade. \\
\hline
\end{tabular}

Fonte: Autor.

No que se refere ao tema Robótica Educacional fica evidente o desconhecimento da turma sobre a abrangência do tema, ao que se propõe e o que é de fato. Embora todos concordem que plenamente que trabalhos neste sentido visam desenvolver a criatividade e o raciocínio lógico, não conseguem formular uma definição para o termo.

É unânime também que a escola não utiliza qualquer ferramenta robótica no contexto educacional. Reflexo disto, é que os professores também não sabem explicar como este tipo de objeto poderia ser utilizado a favor da educação básica.

A turma retrata a seguinte situação: "Existem ações do governo para incluírem os professores em cursos de robótica, porém, o nosso tempo é limitado, estas ações são postas em horários que não são aqueles que estamos em sala de aula e por isto, sempre temos dificuldades de participar". Relato este, apresentando um quadro governamental que propõe ações e formações para inclusão da robótica em sala de aula, porém, tornando custosa a adesão pela maioria absoluta dos professores. A atividade realizada no momento inicial da formação, foi uma importante oportunidade para conhecer a turma, trazendo respostas enriquecedoras para os processos subsequentes a serem implementados nas oficinas, aproximando o pesquisador e a turma de professores, os quais, conforme demonstrado na Figura 4, puderam sentir-se livres para discutir abertamente seus conhecimentos com os demais colegas na procura por responder os questionamentos.

O processo de discussão conjunta sobre as questões postas, no sentido de formalizar uma definição da turma, os colocou no papel de indagar as respostas uns dos outros, dando abertura para um momento de troca de experiências sobre o que entendiam do assunto, sobre as possibilidades do contexto e sobre como cada um dos mesmos se utilizava disso em benefício próprio na sala de aula, quando de fato utilizavam.

O principal objetivo desta etapa era compreender como os professores participantes das oficinas de formação percebem o contexto educacional aqui estudado e entender os limites de 
seus conhecimentos sobre o assunto. Após a realização da etapa é possível apontar que foi possível identificar o conhecimento prévio da turma, situações de uso dos recursos e possíveis facilidades ou dificuldades desde o entendimento do conceito à utilização no processo educativo.

Figura 4 - Turma discutindo suas concepções prévias.

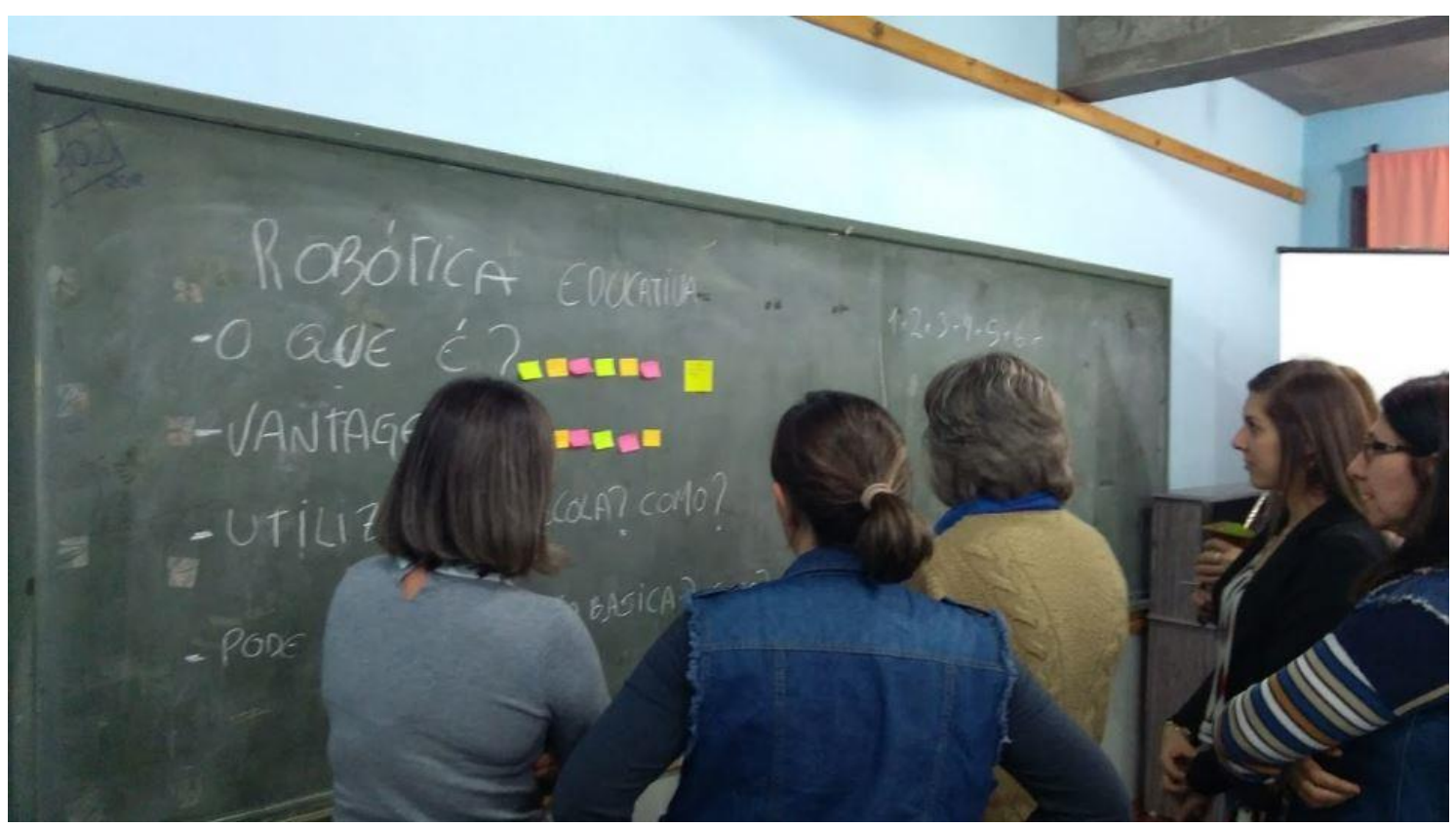

(Fonte: Autor)

\section{Atividades para entendimento do Pensamento Computacional}

As atividades envolvendo o Pensamento Computacional trouxeram um ótimo envolvimento da turma, alinhando atividades lúdicas, exercidas sob o contato com o meio físico, com um viés em experiências para o desenvolvimento da compreensão do tema e das habilidades que o formam. Previamente às atividades, foram realizadas explanações apresentando o cenário e o contexto que engloba o Pensamento Computacional e suas técnicas, de forma que a turma conseguisse compreender o verdadeiro sentido e o direcionamento das atividades práticas que iriam realizar em seguida.

Conforme previsto na sequência didática, todas as lições práticas foram realizadas longe das telas de computador, a exemplo do code.org, o qual disponibiliza as atividades online, as quais foram impressas e organizadas em folhas de ofício, com respectivo espaço para inserção dos blocos coloridos na busca de formar a solução dos exercícios, permitindo uma maior interação com interfaces físicas e maior contato visual, conforme Figura 5.

Um dos professores manifestou o seguinte: "No computador abre-se possibilidade de tentativa e erro para os alunos, então, muitas vezes eles simplesmente vão errando até que o sistema apresenta a solução, sem a necessidade de realmente tentar resolver o problema. Ocorrem casos onde os nossos alunos nos dizem: - Professora, é só ir errando até descobrir. No caso das atividades com material físico, não existe possibilidade de chegar a uma solução pela eliminação de respostas e resultados, sendo necessário de fato pensar na solução antes de aplicá-la e verificar se está ou não correta". 
Abaixo, na Figura 5, a turma de professores encontra-se realizando as lições 10,11 e 13 da etapa "4. Labirinto: Sequência", reforçando o conceito de Algoritmos.

Figura 5 - Turma realizando atividades do Code.org em material físico.

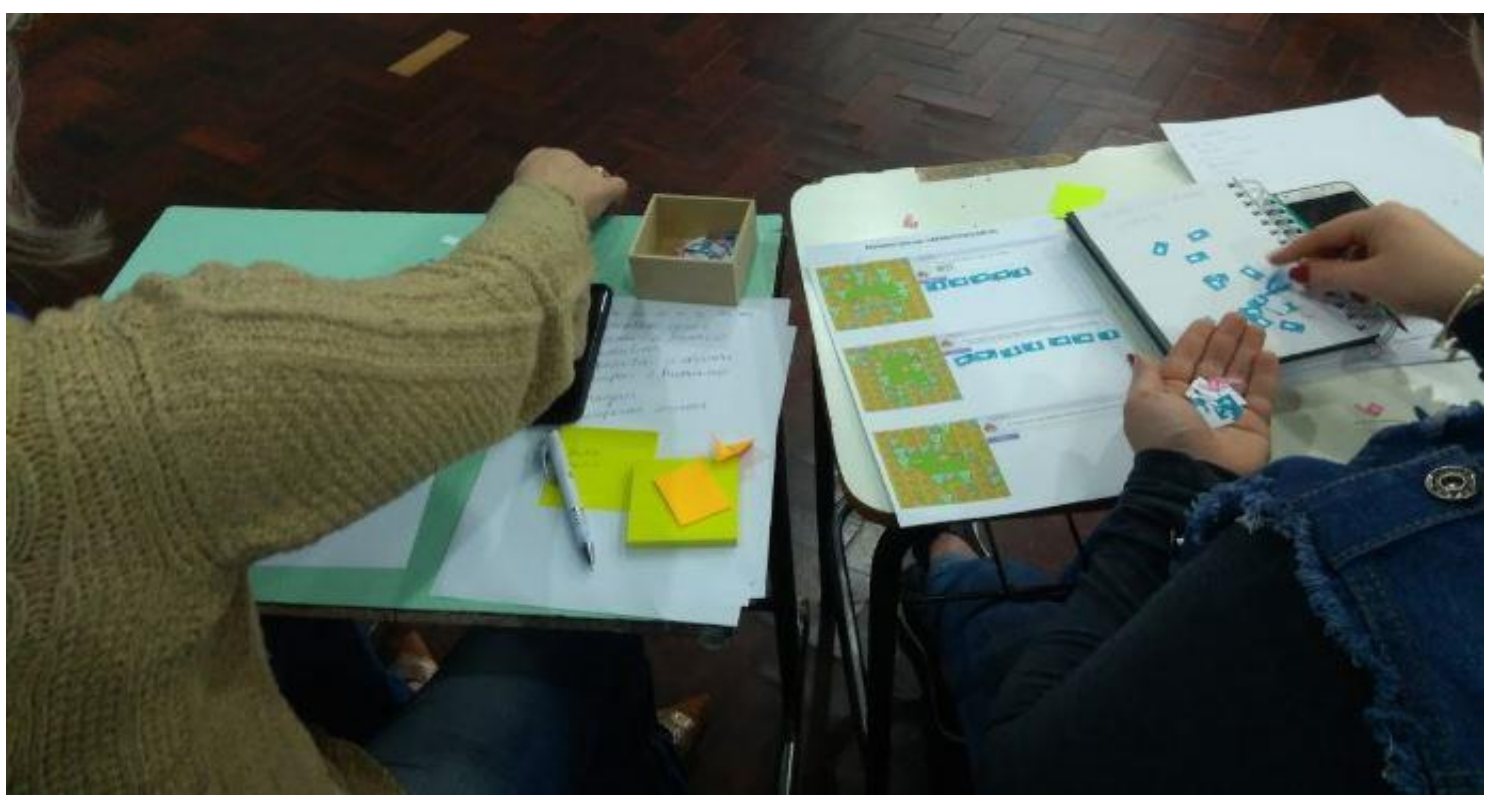

(Fonte: Autor)

Logo após, na Figura 6, é possível perceber as resoluções para as lições 7, 10 e 12 da etapa "13. Labirinto: Laços", trabalhando conceitos de Reconhecimento de Padrões e Algoritmos.

Figura 6-Atividades para reconhecimento de padrões e algoritmos.

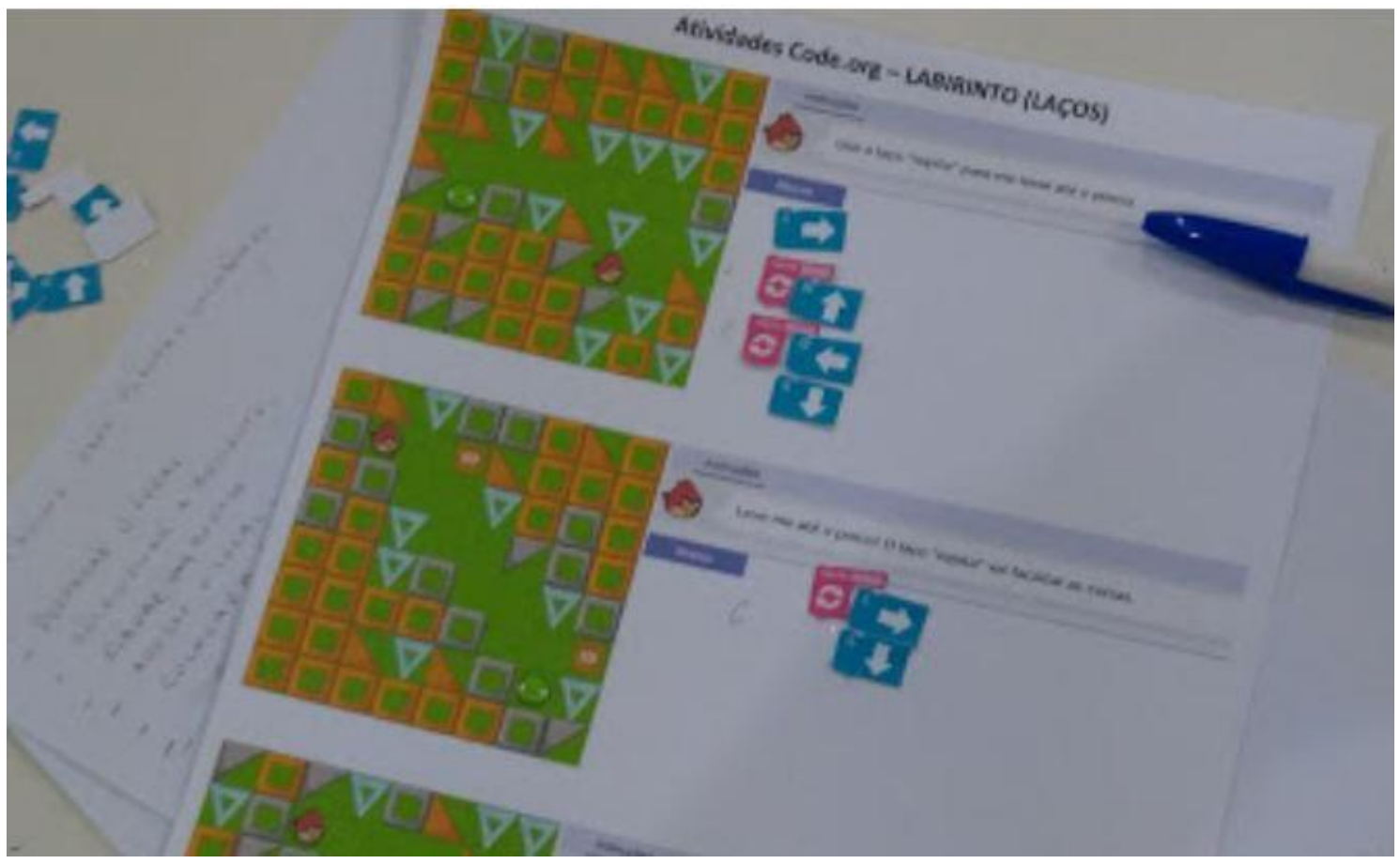

(Fonte: Autor)

Realizaram-se discussões com intuito de verificar a compreensão da turma a respeito dos exercícios e dos seus propósitos, momento o qual foi de descontração, onde alguns, não conseguiram perceber logicamente a forma de resolver os problemas propostos, ao contrário 
de outros, os quais entenderam e compreenderam como chegar aos resultados e como os exercícios deste tipo colocam seus alunos na busca pela aprendizagem.

A turma de professores diz que seus alunos prestam mais atenção ao trabalharem em atividades envolvendo objetos coloridos: - "Eles querem brincar o dia todo com os Legos se Ihes é permitido, e percebemos o quanto estas ferramentas coloridas prendem a atenção destes alunos de menor idade. Porém, para isto o aluno deve ter persistência, não se dispersar com outros eletrônicos e afins".

O objetivo desta etapa era capacitar a turma para compreender os princípios e habilidades que formam o conceito de Pensamento Computacional, subsidiando o processo subsequente, com intuito de obter melhores resultados no processo de formação docente e uma aprendizagem mais significativa. Após a realização da etapa é possível apontar que a turma de professores teve um ótimo engajamento com prática das atividades propostas, ficando perceptível como todos sentiram-se desafiados a resolverem os problemas impostos, com total atenção voltada aos exercícios e desejo absoluto de chegar à solução correta.

\section{Atividades com Robô Cubetto e seu Kit de Robótica}

Primeiramente, foi apresentado o Robô Cubetto e seus componentes, explicando seu funcionamento para a turma de professores, os quais, imediatamente demonstraram interesse em descobri-lo, fazer testes e vê-lo em movimento. Todos foram oportunizados a programar previamente o Cubetto, de maneira a entender como fazê-lo se movimentar e como redirecionar o mesmo para a rota desejada nos momentos corretos.

Ao se realizarem as atividades com o Robô Cubetto, seu Kit de Robótica e demais ferramentas, demonstrado na Figura 7, ficou evidenciado, que cada professor, ao utilizar e praticar com o objeto robótico assumiu a multidisciplinaridade da ferramenta, embora, claro, elaborando uma visualização própria, voltada para suas áreas de ensino. Conseguiram perceber formas de trabalhar atividades variadas mesclando disciplinas, bem como, idealizaram diversas possibilidades voltadas, cada uma, para seu campo de atuação.

Figura 7-Atividades com o Robô Cubetto.

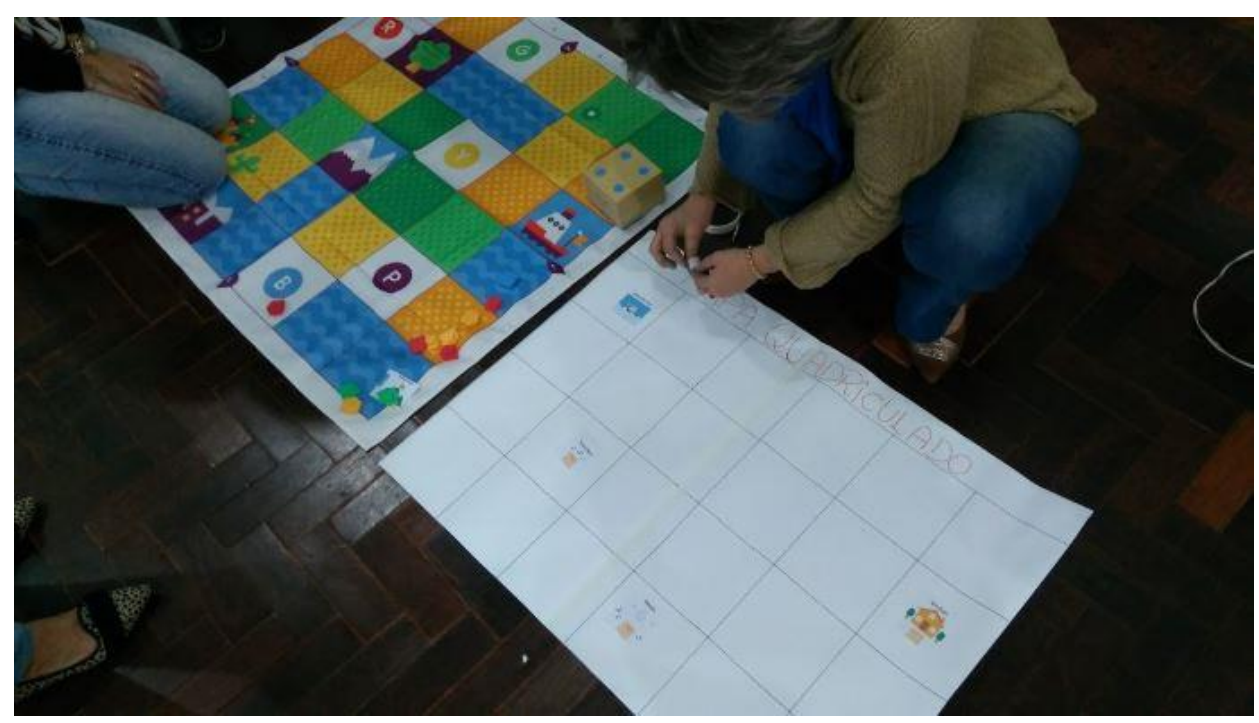

(Fonte: Autor) 
Na figura acima, conforme previsto na sequência didática, os professores estão realizando o desafio de resolver o algoritmo que leva o Cubetto durante uma viagem, com passagem pelos recortes dos dias da semana até o retorno para casa. Todos foram engajados no desafio, desde a distribuição dos dias da semana que formariam a rota a ser realizada no mapa, passando pelas discussões de como iriam programar o Cubetto, até o acompanhamento da solução, verificando se o desafio foi concluído, discutindo os erros e realizando as correções do algoritmo.

Com isto, ficou explícito o poder da ferramenta em reunir um grupo para trabalho em equipe, possibilitando que discutam soluções, realizem questionamentos e exercitem o raciocínio lógico na busca constante por resolver os desafios propostos. Ainda assim, a turma mostrou-se um tanto quanto angustiada em relação à esta nova possibilidade de ensino, se iriam conseguir abordar estas ferramentas com os alunos em sua plenitude e se conseguirão tornar o processo de aprendizagem relevante, inserindo o aluno como construtor do próprio conhecimento.

Uma das professoras se questiona: " - Eu vejo aqueles pequenos desde cedo, participando de mudanças muito rápidas, será que eles vão dar conta?", enquanto outra colega da turma preocupa-se: "- Será que vamos utilizar a ferramenta de uma forma que direcione o aluno para a construção do conhecimento, será que vamos direcionando o aluno para a melhor educação e novas descobertas? Têm algumas experiências onde utilizam algumas tecnologias, principalmente os dispositivos móveis, que acabam dispersando e invertendo o objetivo dos papéis".

Porém, para os professores, ao tratar-se de crianças e alunos de pouca idade, entre 4 e 5 anos, onde alguns já vivenciaram experiências, é perceptível a maior facilidade na inserção de ferramentas como o Cubetto, pois estas crianças, segundo eles: "são os mais receptíveis realmente a atividades com ambiente físico, blocos coloridos de encaixe e outros objetos semelhantes".

$\mathrm{Na}$ sequência da formação docente, como última atividade, foi proposto o desenvolvimento de exercícios pelos próprios professores, sendo esta, uma das formas de medir a maneira como estes utilizaram-se deste momento para apropriar-se do objeto de estudo. 0 exercício desenvolvido e demonstrado na Figura 8 teve o intuito de desenvolver a capacidade de raciocínio ao mesmo tempo que ensina a escrever através de sílabas. A ideia seria desenvolver um quadro quadriculado, no qual seriam distribuídas diversas sílabas aleatórias. 0 professor responsável coloca uma palavra no quadro negro e desafia os alunos a realizarem a programação do Robô Cubetto de forma que consiga percorrer caminhos que o levem a passar pelas sílabas que formam a palavra.

No exercício acima, com apenas algumas sílabas utilizadas para exemplo, é possível desafiar a busca pela palavra "Macaco" fazendo relação ainda com temas de aula, onde os professores possam estar ensinando a fauna e a vida animal para seus alunos. É possível programar o Robô Cubetto para que pare a cada sílaba encontrada ou que percorra o caminho inteiro passando pelas mesmas, de acordo com a necessidade ou entendimento do professor sob o que seria o melhor andamento do exercício. Além desta atividade criada, professores da 
área de Geografia ainda identificaram possibilidades de trabalharem as coordenadas geográficas e o sistema cartesiano com suas turmas de alunos.

Figura 8 - Exercício criado pela turma durante a oficina de formação.

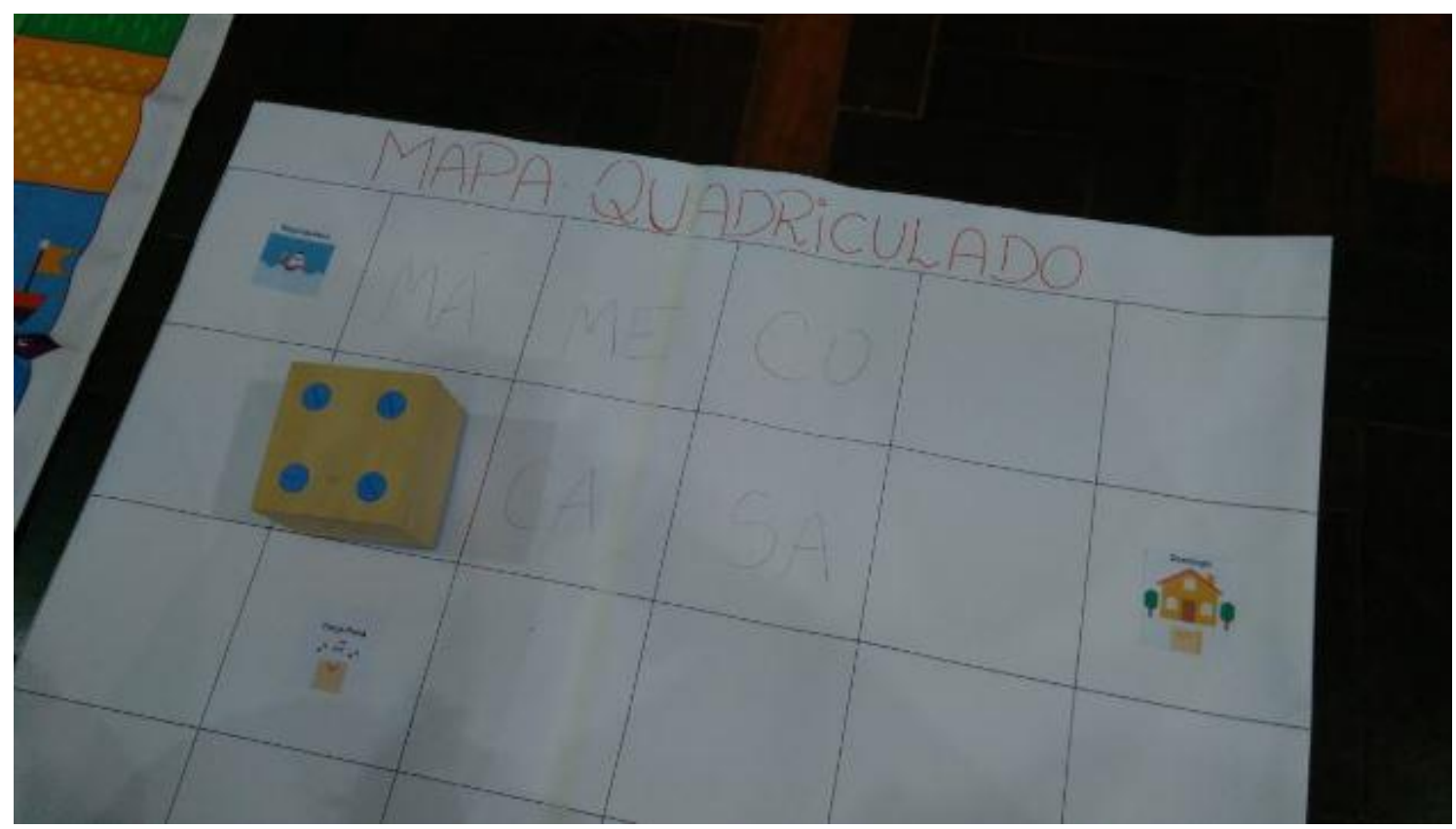

(Fonte: Autor)

Ao final percebeu-se os professores extremamente entusiasmados ao utilizarem o Robô Cubetto e seu Kit de Robótica, os quais entendem que a ferramenta realmente chama a atenção pelos blocos coloridos e pela interface totalmente voltada para as crianças da educação básica. No entanto, uma das dificuldades percebidas pela turma seria o custo benefício, já que seriam necessários mais de um kit para uma aprendizagem realmente significativa, de maneira que possam envolver todos os alunos nos desafios propostos. Questionam se as escolas teriam possibilidade de proporcionar estes objetos ou realizar a aquisição dos mesmos, frente a uma realidade de cortes, principalmente escolas públicas que trabalham com recursos escassos.

O objetivo desta etapa era que a turma de professores fosse capaz de participar de atividades educativas para a educação básica realizando práticas com uma ferramenta robótica tangível, longe das telas do computador, tendo por principal finalidade, que os mesmos conseguissem apropriar-se deste recurso didático e compreender como tal objeto ou afins podem ser importantes auxiliadores para um fazer diferenciado no processo de ensino desde as idades iniciais. Após a realização da etapa, entendemos que a turma se apropriou da ferramenta e conseguiu compreender como estes recursos podem ser poderosos meios de fornecer uma aula diferenciada, abrangendo uma diversidade de possibilidades em cada área de ensino.

\section{Considerações dos professores entrevistados}

Ao final do processo de formação docente, o último momento das oficinas, foi a realização de uma roda de discussão e entrevistas junto aos professores, buscando trabalhar e obter respostas para as questões prévias deste trabalho de pesquisa, as quais buscam entender o posicionamento dos professores perante ao contexto do estudo logo após às práticas realizadas, de maneira que também seja possível relacionar seus conhecimentos prévios com a 
aprendizagem que de fato a formação Ihes proporcionou. Abaixo uma breve análise a respeito de cada uma das questões da entrevista:

\section{A formação de professores para a utilização da robótica como meio educacional permite aos docentes se apropriarem desta tecnologia?}

Os professores, ao serem questionados sobre a possibilidade de se apropriarem e utilizarem a tecnologia robótica como meio educacional, colocam que "tendo as ferramentas a disposição não teriam porque não as utilizar, e que sim, de fato eles iram utilizar, percebendo as vantagens proporcionadas, como multidisciplinaridade, estímulo ao raciocínio lógico, estímulo da criatividade e do desenvolvimento de habilidades de resolução de problemas. Porém, precisam das ferramentas adequadas, de momentos como estes, onde são proporcionadas formações para que possam aprender e principalmente que tenham tempo de aula disponível para este fazer educacional diferenciado".

Foi possível sentir que a turma de professores percebe bem a dificuldade da sua realidade de escola pública, onde os esforços para apoiar este tipo de iniciativa são os mínimos, e com isto, entendem que deveriam ter maior apoio da iniciativa pública trazendo este tipo de ferramenta para sala de aula, ou, que fosse possível obter objeto semelhante ao do estudo com baixo custo de aquisição ou construção - esta foi uma das discussões, onde os professores questionam o custo real para obtenção do Robô Cubetto e seu Kit de Robótica, o que em primeiro momento os assustou. Dizem os professores que "olhando para os pequenos, para as crianças, realmente acham possível a apropriação da ferramenta, porém, também entendem que deveriam ter ferramentas como esta disponibilizadas a baixo custo".

Ao tratar do tempo para trabalhos diferenciados utilizando a robótica, foi unânime entre a turma que deveriam ter aulas em tempo integral para conseguirem abordar todo o conteúdo presente na grade curricular e ainda trabalhar outros aspectos de como os alunos aprendem e desenvolvem sua criatividade. Abordam "que nem todo o conteúdo tem como ser transformado neste tipo de atividade, o conteúdo também tem que ser dado em completude. Mediante a realidade em que vivem, com turno reduzido (não integral), se torna complicado, pela necessidade de cumprir as disciplinas obrigatórias e seus planos de aula. Desta forma, o turno integral é visto como essencial para o processo".

\section{A utilização do Robô Cubetto permite estimular o ensino da lógica e programação de computadores nas crianças?}

Respostas mais diretas demonstram a opinião positiva dos professores no que diz respeito ao estímulo da lógica e programação de computadores para crianças a partir da utilização do Robô Cubetto, os quais dizem "sim, com certeza a lógica e o raciocínio são estimulados, ainda mais com esta ferramenta onde os alunos têm que pensar antes, colocar ali todo o plano para solução, para somente depois descobrir o resultado".

\section{Com o apoio do Robô Cubetto no ensino, é possível contribuir para o aprendizado de outras disciplinas?}

Os professores apontaram que sim, o Robô Cubetto permite contribuir para o aprendizado de outras disciplinas, bem como demonstraram que o trabalho permitiu a 
visualização de cada um considerando a sua especialidade, de alguma forma de aprendizagem sob a ótica da disciplina de domínio.

Um dos professores ao refletir sobre o questionamento disse: "Sim, com certeza proporciona o aprendizado de outras disciplinas. Eu me vi muito na Geografia. Acho que cada um de nós viu sua matéria, sua disciplina e a possibilidade de fazer algo voltado para a mesma".

Neste sentido, o próprio desenvolvimento de uma atividade pelos professores, descrita nas seções anteriores, onde demonstraram que utilizando Robô Cubetto seria possível contribuir para o ensino das sílabas, demonstra que a turma percebeu as contribuições da ferramenta para o aprendizado das disciplinas. Através do exercício com as sílabas, uma das possibilidades destacadas seria de estudos sobre a fauna e flora com a formação de palavras no mapa quadriculado, bem como, alguns ainda destacaram as possibilidades de trabalharem as coordenadas geográficas e o sistema cartesiano.

Os blocos de códigos gráficos, representados através de uma interface física, são importantes para manter a criança atenta na realização das tarefas propostas pelo cenário apresentado?

Os entrevistados concordaram sobre a importância dos códigos coloridos e da interface física no papel de manter a atenção das crianças, os quais dizem que "tudo que é colorido chama mais a atenção das crianças. De fato, neste caso, os blocos diferenciam a posição para qual o Robô irá andar facilitando também no entendimento das crianças".

Você acredita que é possível chamar a atenção das crianças da educação básica utilizando a robótica como objeto de ensino e com isto aumentar a motivação por parte das crianças ao se depararem com a necessidade de resolver os problemas lógicos?

Respondendo às duas últimas perguntas da entrevista, os professores acreditam que sim, é totalmente possível a utilização da robótica para chamar a atenção das crianças desafiandoas com atividades diferenciadas e com isto fazer com que os alunos tenham um aumento de motivação na tentativa de resolução dos desafios propostos. Porém, preocupam-se com a "falta de paciência de algumas crianças, que pode ser um risco ao modelo de aprendizagem ofertado, onde, neste caso, devem desenvolver a solução, tendo de esperar para verificar se conseguiram ou não resolver o problema de maneira correta. As crianças desta geração são muito para agora, querem as coisas na hora, são imediatistas". Um professor brinca que é "possível que peçam para ver se teria como acelerar o Robô". Outro cita que talvez "os alunos iriam brincar e colocar de qualquer jeito, apenas para ver o robô andar".

\section{Considerações Finais}

O contexto atual em que vivemos requisita que os estudantes da educação básica sejam estimulados para o desenvolvimento do raciocínio lógico e da capacidade de serem criativos desde as idades iniciais do ensino, o que irá lhes permitir maior capacidade para resolver problemas complexos, problemas reais. Neste sentido, o papel do professor, cada vez mais, é de desenvolver uma aula instigadora, que consiga colocar os alunos no papel de questionadores, 
de construtores de seus próprios conhecimentos. Para tanto, as ferramentas tecnológicas, como por exemplo, a robótica, podem ser poderosos recursos na contribuição para um fazer educacional diferenciado, oportunizando um ensino multidisciplinar.

Neste cenário, o kit de Robótica Cubetto, recurso do qual se tem poucos registros na literatura no âmbito educacional, pode se tornar um poderoso aliado aos professores da educação básica, proporcionando uma gama de possibilidades de realização de trabalhos no sentido de desenvolver habilidades indispensáveis para o crescimento de seus alunos, tornandoos capazes de resolver problemas complexos, criarem soluções reais para a vida cotidiana e se tornarem agentes ativos na construção do conhecimento. O Cubetto, além de suas atividades propostas, conforme demonstrado no texto, ainda mantém aberto um leque para que os próprios professores possam criar suas próprias atividades longe das telas do computador, cada uma voltada para a área de ensino desejada, a qual se deseja atingir determinados objetivos.

Outros aspectos destacáveis do recurso didático se referem a um ensino lúdico, utilizando blocos coloridos, os quais, de acordo com o que foi apresentado no texto, aproximam os alunos das idades iniciais, que tem sua atenção voltada às atividades propostas, se sentindo desafiados a resolver os problemas propostos. Porém, provavelmente, uma das dificuldades de sua inclusão na educação seja o custo de aquisição, preocupação dos professores no sentido da situação econômica atual, se questionando se todas as escolas conseguiriam proporcionar este recurso de maneira que atenda ao ensino de todos os alunos.

Por fim, é importante destacar o processo de formação docente realizado, a partir do qual ficou evidenciado como os professores conseguiram absorver as atividades realizadas, se apropriando dos recursos robóticos trabalhados, de maneira que por si próprios já realizaram a criação de atividades e conseguiram explorar a ferramenta com ideias de fazeres educacionais voltados para suas disciplinas de domínio. Desta forma, percebemos que um processo formativo buscando aproximar os professores das novas ferramentas tecnológicas, bem como a robótica, pode ser um excelente caminho para conscientizá-los de quão úteis podem ser estes recursos e capacitá-los para a melhor utilização em sala de aula.

\section{Referências}

AGUIAR, Y. Q. et al. Introdução à Robótica e Estímulo à Lógica de Programação no Ensino Básico Utilizando o Kit Educativo LEGO ${ }^{\circledR}$ Mindstorms. Anais dos Workshops do Congresso Brasileiro de Informática na Educação (CBIE). Maceió - AL: Sociedade Brasileira de Computação - SBC. p. 1418-1424, 2015.

DE OLIVEIRA, G. A. A. et al. GrubiBots Educacional: jogo para o ensino de algoritmos na educação básica. Brazilian Symposium on Computers in Education (Simpósio Brasileiro de Informática na Educação - SBIE). Dourados - MS: Sociedade Brasileira de Computação - SBC. p. 584. 2014.

DOS SANTOS, D. C., STROHSChOEN, A. A. G. Percepção Docente Sobre o Uso das Tecnologias da Informação e Comunicação no Processo de Ensino. Revista Tecnologias na Educação, ano 10, vol 25, 2018. 
LIMA, E. R. P. O., MOITA, F. M. G. S. C. A tecnologia e o ensino de química: jogos digitais como interface metodológica. In: Tecnologias digitais na educação. EDUEPB, p. 130-154, 2011.

MORAIS, P. H., MORAIS, B. T., MORAIS, M. C. Os Professores de Uma Escola Estadual De Angicos-RN Frente às Tecnologias da Informação e Comunicação: A Utilização das TICs em Suas Práticas Pedagógica. Revista Tecnologias na Educação, ano 10, vol 25, 2018.

PRIMO. Cubetto: A toy robot teaching kids code $\&$ computer programming. Disponível em: https://www.primotoys.com. Acesso em: 26 out. 2017.

QUEIROZ, R. L., SAMPAIO, F. F. DuinoBlocks For Kids: Um ambiente de programação em blocos para o ensino de conceitos básicos de programação a crianças do Ensino Fundamental I por meio da Robótica Educacional. Anais do Congresso da Sociedade Brasileira de Computação (CSBC). Uberlândia - MG: Sociedade Brasileira de Computação - SBC. p. 2086-2095, 2016.

RAMOS, J. L., ESPADEIRO, R. G. Os futuros professores e os professores do futuro. Os desafios da introdução ao pensamento computacional na escola, no currículo e na aprendizagem. Revista Educação, Formação \& Tecnologias, v. 7, n. 2, p. 4-25, 2014.

REIS, R. S., LEITE, B. S., LEÃO, M. B. C. Apropriação das Tecnologias da Informação e Comunicação no ensino de ciências: uma revisão sistemática da última década (2007-2016). RENOTE - Revista Novas Tecnologias na Educação, v. 15, n. 2, 2017.

WYETH, P; WYETH, G. F. Electronic blocks: Tangible programming elements for preschoolers. International Conference on Human-Computer Interaction (INTERACT'01). Tokyo - Japan: Hirose, M. p. 496-503, 2001. 